\title{
Pitcairnia L'Hér. (Bromeliaceae): uma nova espécie, P. azouryi Martinelli \& Forzza, e observações sobre P. encholirioides L. B. Sm.
}

\author{
GUSTAVO MARTINELLI ${ }^{1}$ e RAFAELA CANPOSTRINI FORZZA ${ }^{1,2}$
}

(recebido: 23 de dezembro de 2005; aceito: 5 de outubro de 2006)

\begin{abstract}
Pitcairnia L'Hér. (Bromeliaceae): a new species, P. azouryi Martinelli \& Forzza, and notes on P. encholirioides L. B. Sm.). A new species of Pitcairnia from the east coast of Brazil is described and illustrated. P. azouryi can be differentiated from all other Brazilian species of the genus by possessing large flowers (10-18 cm long) which are reflexed after fecundation, blades deciduous by an abscission zone 4-6.5 cm above the sheath, aculeate only at the marcescent portion. A detailed description and illustration of P. encholirioides L.B.Sm., a species endemic to Rio de Janeiro State only known from the type collection and from its poor diagnoses, are also presented.
\end{abstract}

Key words - Bromeliaceae, inselbergs, Pitcairnioideae, taxonomy

RESUMO - (Pitcairnia L'Hér. (Bromeliaceae): uma nova espécie, P. azouryi Martinelli \& Forzza, e observações sobre P. encholirioides L. B. Sm.). Uma nova espécie de Pitcairnia oriunda da costa leste do Brasil é descrita e ilustrada. P. azouryi, pode ser diferenciada das demais espécies brasileiras do gênero por apresentar flores muito desenvolvidas (10-18 cm compr.) e reflexas após a fecundação, lâmina decídua por zona de abscisão 4-6,5 cm acima da bainha, aculeada somente na porção marcescente. Também é apresentada a descrição e ilustração de $P$. encholirioides L.B.Sm., espécie endêmica do Rio de Janeiro e até então conhecida apenas pela coleção-tipo e por sua diagnose, que não contemplava todos os caracteres relevantes para definir a espécie e são aqui descritos.

Palavras-chave - afloramentos rochosos, Bromeliaceae, Pitcairnioideae, taxonomia

\section{Introdução}

Pitcairnia (sensu lato) com cerca de 350 espécies é o maior e o mais amplamente distribuído gênero de Pitcairnioideae (Bromeliaceae), ocorrendo no México, América Central, Antilhas e por quase toda a América do Sul, com a maior riqueza de espécies na região andina (Smith \& Downs 1974, Luther 2004). Para o Brasil, Smith \& Downs (1974) citaram 28 espécies. Após esta obra, algumas novas espécies foram descritas, alguns táxons foram sinonimizados e novas ocorrências foram registradas, principalmente na região limítrofe do Brasil com a Venezuela (Wendt \& Chamas 1997, Holst 1997, Wendt et al. 2000, Luther 2004, Tatagiba et al. 2004). Assim, atualmente 43 espécies podem ser contabilizadas para o território brasileiro.

O presente trabalho tem por objetivo apresentar uma nova espécie do gênero procedente do Espírito Santo, Pitcairnia azouryi, e a descrição de P. encholirioides, até então conhecida apenas pelo holótipo, coletado em 1934, e por uma diagnose que não contempla todos os caracteres diagnósticos da espécie.

\footnotetext{
1. Jardim Botânico do Rio de Janeiro, Pacheco Leão 915, 22460-030 Rio de Janeiro, RJ, Brasil.

2. Autor para correspondência: rafaela@jbrj.gov.br
}

\section{Resultado e Discussão}

As espécies de Pitcairnia registradas para o Brasil possuem padrões de distribuição bem definidos por províncias fitogeográficas (Wendt \& Chamas 1997). Levantamentos preliminares em herbários e literatura indicam que nos domínios da floresta amazônica ocorrem 18 espécies, quase exclusivas dessa região. Nos domínios do cerrado podem ser encontradas cerca de 10 espécies, principalmente nos estados de Goiás, Minas Gerais e Mato Grosso. Na costa leste do Brasil são encontradas cerca de 15 espécies (incluindo a aqui descrita), que ocorrem especialmente nos campos de altitude e nos "inselbergs" nos domínios da floresta atlântica, sendo o Rio de Janeiro o estado de maior diversidade, com nove espécies. Dentre os táxons da costa leste, merece destaque o "complexo Pitcairnia flammea", que envolve muitas variedades e que necessita de revisão, o que possivelmente levará a uma modificação do número de espécies para esta área.

Pitcairnia azouryi Martinelli \& Forzza sp. nov. Tipo: BRASIL. Espírito SAnto: Cachoeiro do Itapemirim, Fazenda Mangabeira, Pedra da Andorinha, afloramento rochoso com Alcantarea, Vellozia e Trilepsis, 2046'59" S e 41 20'94" W, elev. 130 m, 31-VIII-2004, 
fl., fr., G. Martinelli 15977 (holótipo RB, isótipos CEPEC, K, MBM, MO, NY, SP, SPF, US).

Figura 1

Ab omnibus speciebus generis bulbis $14-17 \mathrm{~cm}$ longis, circa $25 \mathrm{~cm}$ diam, lamina decidua abscicionis zona 4-6,5 cm supra vaginam, aculeata solum in parte marcescenti, floribus $10-18 \mathrm{~cm}$ longis, alabastris erecto-patentibus, floribus $10-18 \mathrm{~cm}$ longis, reflexis post fecundationem, fructibus reflexis differt.

Erva rupícola, heliófila, 1,5-1,7 m alt.; caule compacto, formando numerosos estolões radiais com 18-30 cm compr. Folhas monomorfas, ereto-arqueadas; bainhas externas marcescentes, castanhas, cartáceas, lepidotas no terço superior da face abaxial, tricomas alvos, margem inteira bainhas internas alvas, suculentas, formando um bulbo; bulbos $13-18 \mathrm{~cm}$ compr., com até $30 \mathrm{~cm}$ diâm.; lâmina foliar 50-72 × 2,2-2,6 cm, decídua, com zona de abscisão evidente, $4-6,5 \mathrm{~cm}$ acima da bainha, verdes, lanceolada, ápice longo-atenuado, margem aculeada somente na parte marcescente da lâmina, esparsamente alvo-lanosa próximo à bainha. Escapo 0,85-1,5 m compr., verde, alvo-lanuginoso; brácteas muito mais longas que os entrenós, lanceoladas, verdes, ápice longo-atenuado, alvo-lanuginosas. Inflorescência 35-55 cm compr., simples, ereta, multiflora, com coma de brácteas estéreis no ápice; raque verde a castanho-avermelhada, alvo-lanuginosa; brácteas florais 2,2-5,5 ×0,8-1,2 cm, menores que as flores, lanceoladas a oval-lanceoladas, alvo-lanosas, verdes, as vezes com máculas avermelhadas esparsas, ápice atenuado. Flores 10-18 cm compr., zigomorfas, pediceladas, em botão e início de antese ereto-patentes, passando a reflexas após a fecundação; pedicelo 1-1,8 cm compr., alvo-lanoso, verde, as vezes com máculas avermelhadas; sépalas 3,6-4,2 × 1-1,2 cm, lanceoladas, alvo-lanosas, verdes com máculas vermelhas especialmente na porção central, ápice agudo; pétalas 9,2-15,2 × 0,7-1,2 cm, lanceoladas, glabras, no início da antese com terço inferior creme-esverdeado, terço superior creme-esverdeado com máculas vermelhas, nigrescentes e espiraladas após a fecundação, ápice agudo, simétrico; estames parcialmente exsertos pela posição das pétalas, amarelos; filetes 4,9-11,5 cm compr.; anteras 2,1-2,3 cm compr., lineares, base levemente sagitada; gineceu verde; ovário 1,1-1,4 cm compr., 3/4 ínfero; estilete 7-14,2 cm compr.; estigma 4-7 $\mathrm{mm}$ compr., conduplicado-espiralado. Frutos 1,8-2,3 cm compr., c. de $1,5 \mathrm{~cm}$ diâm., arredondados, castanhos, reflexos, perianto persistente; sementes c. de $5 \mathrm{~mm}$ compr., castanhas, lineares, bicaudadas, com superfície da ala e do corpo com padrão celular distinto.

Material adicional examinado: BRASIL. EsPÍRITO SANTo: Cachoeiro do Itapemirim, Fazenda Mangabeira, Pedra da Andorinha, afloramento rochosos com Alcantarea, Vellozia e Trilepsis, 2046'59" S e 4120'94" W, elev. $120 \mathrm{~m}, 16$-VIII-1999, bt., G. Martinelli et al. 15745 (RB).

Pitcairnia azouryi, quando fértil, chama atenção pelo tamanho das flores e a posição reflexa destas após a antese (figura 1C). Tais caracteres florais só haviam sido observadas em espécies andinas (e.g. P. ferruginea Ruiz \& Pav., P. lanuginosa Ruiz \& Pav. e $P$. trianae André), sendo reportadas pela primeira vez para uma espécie brasileira de Pitcairnia. Entretanto, $P$. azouryi pode ser facilmente diferenciada das demais espécies do gênero, mesmo quando estéril, por apresentar zona de abscisão da lâmina foliar evidente, 4-6,5 cm acima da bainha, bainhas marcescentes formando um bulbo muito desenvolvido, estolões originando-se radialmente em torno da planta mãe e porção marcescente da lâmina com margem aculeada e reflexa (figura 1A, B).

Os indivíduos dessa nova espécie formam pequenos aglomerados na parte mais baixa do afloramento rochoso em local ensolarado e úmido. O epíteto é uma homenagem ao fotógrafo Ricardo Azoury que participou das expedições de coleta do Projeto Bromélias da Mata Atlântica e registrou com muito talento a beleza destas plantas.

Pitcairnia encholirioides L. B. Sm., Arq. Jard. Bot. Rio de Janeiro 10: 146. 1950. Tipo: BRASIL. RIO DE JANEIRO: Santa Maria Madalena, Pedra das Flores, 4III-1934, fl., fr., J. Santos-Lima \& A. C. Brade 13249 (holótipo RB).

Erva rupícola, heliófila, 1,3-1,7 m alt; estolões curtos, c. de $10 \mathrm{~cm}$ compr. Folhas monomorfas, eretoarqueadas; bainhas externas marcescentes, castanhas, margem inteira, lepidotas na face abaxial, tricomas castanhos, bainhas internas alvas, suculentas, formando um bulbo; bulbos 14-17 cm compr., com até $25 \mathrm{~cm}$ diâm.; lâmina foliar 90-120 × 2,2-3,6 cm, decídua, verde com base avermelhada, lanceolada, margem inteira, glabrescente no terço inferior, glabra nos terços médio e superior, ápice longo-atenuado. Escapo $70-85 \mathrm{~cm}$ compr., verde, vermelho até creme, quase totalmente recoberto por brácteas, glabrescente a alvo-lanuginoso; brácteas muito mais longas que os entrenós, lanceoladas, ápice longo-atenuado, alvo-lanuginosas na base, glabras no terço médio e superior, as basais verdes com terço 


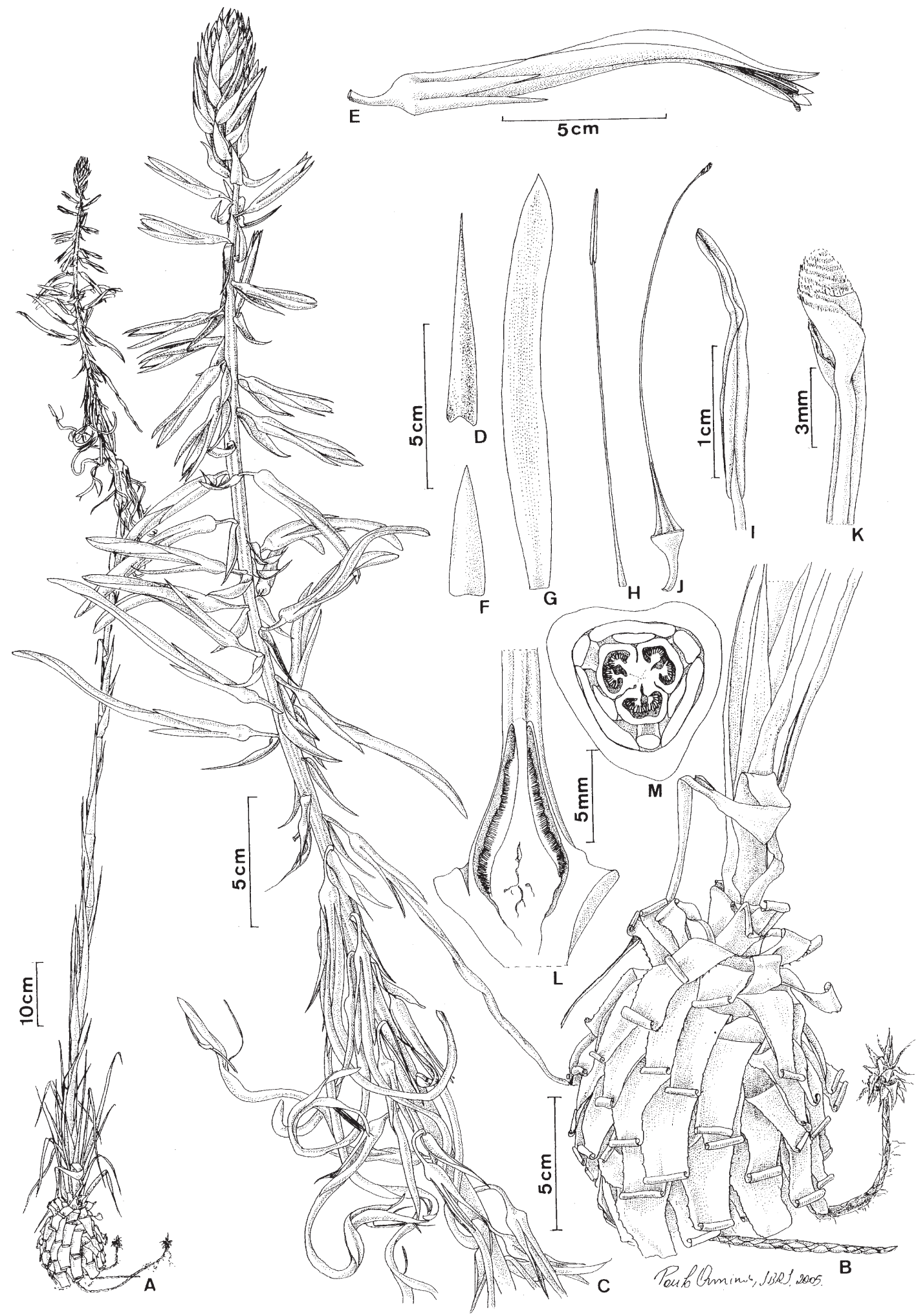

Figura 1. Pitcairnia azouryi Martinelli \& Forzza. A. Hábito e inflorescência. B. Bulbo com bainhas e parte das lâminas marcescentes. C. Inflorescência. D. Bráctea floral. E. Flor. F. Sépala. G. Pétala. H. Estame. I. Antera. J. Gineceu. K. Estigma. L. Corte longitudinal do ovário. M. Corte transversal do ovário.

Figure 1. Pitcairnia azouryi Martinelli \& Forzza. A. Habit and inflorescence. B. Stem with marcescent sheaths and portion of the blade. C Inflorescence. D. Floral bract. E. Flower. F. Sepal. G. Petal. H. Stamen. I. Anther. J. Gynoecium. K. Stigma. L. Longitudinal section of the ovary. M. Transversal section of the ovary. 


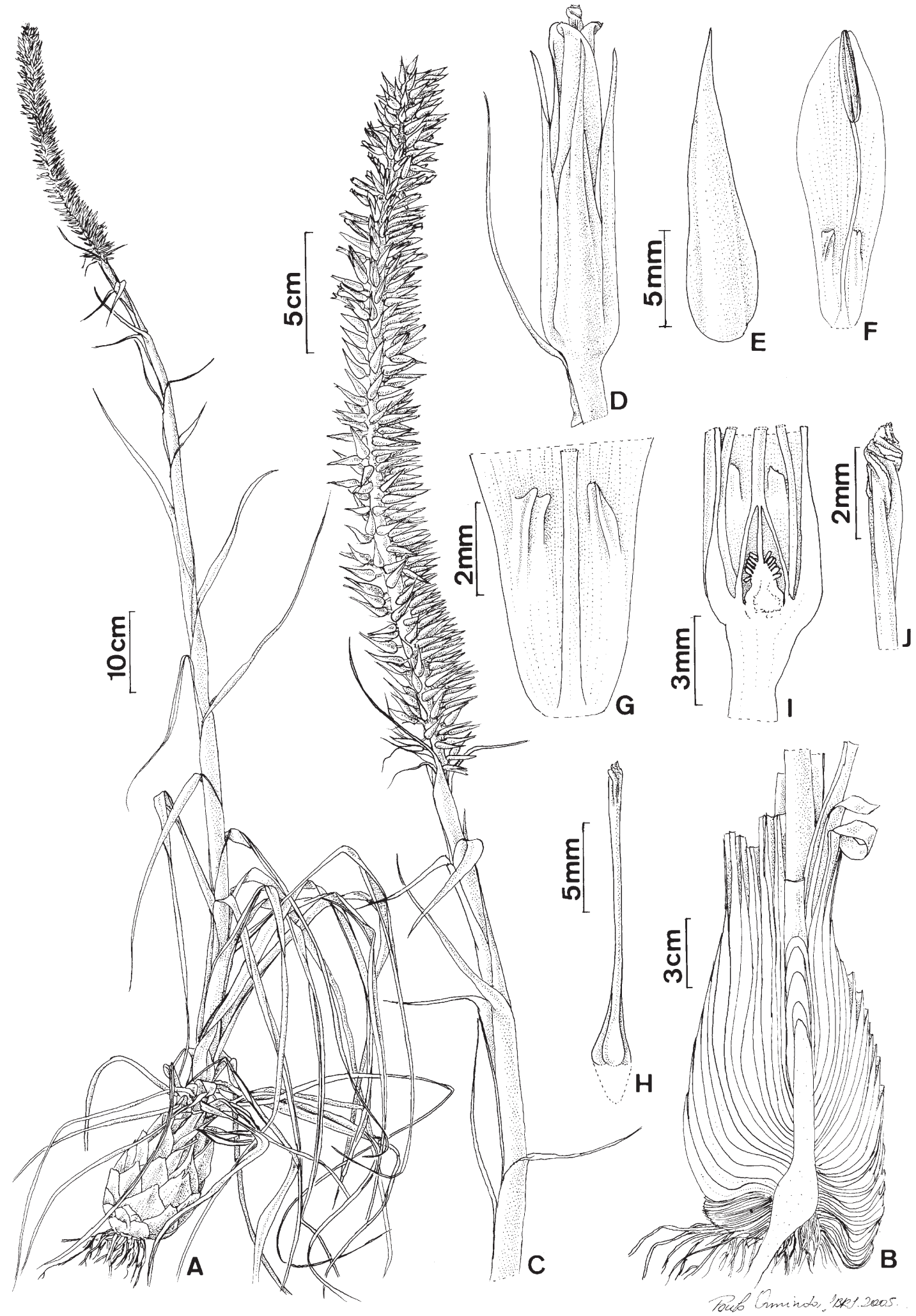

Figura 2. Pitcairnia encholirioides L. B. Sm. A. Hábito e inflorescência. B. Corte longitudinal do bulbo. C. Inflorescência. D. Flor e bráctea floral. E. Sépala. F. Pétala e estame. G. Detalhe dos apêndices petalíneos. H. Gineceu. I. Corte longitudinal da base da flor. J. Estigma.

Figure 2. Pitcairnia encholirioides L. B. Sm. A. Habit and inflorescence. B. Longitudinal section of the bulb. C. Inflorescence. D. Flower and floral bract. E. Sepal. F. Petal and stamen. G. Detail of petal appendages. H. Gynoecium. I. Longitudinal section of the base of the flower. J. Stigma 
inferior avermelhado, as superiores estramíneas. Inflorescência 30-35 cm compr., simples, ereta, multiflora, com coma de brácteas estéreis no ápice; raque vermelha, glabra; brácteas florais 2,2-5 $\times$ $0,1-0,3 \mathrm{~cm}$, excedendo as flores no terço médio da inflorescência até menores ou igualando no terço superior, lineares, estramíneas, glabras, ápice longoatenuado. Flores 2-3 cm compr., actinomorfas, pediceladas, glabras, patentes, passando a eretas após a fecundação; pedicelo 4-6 mm compr., vermelho; sépalas 1,8-2,2 × 0,5-0,6 cm, lanceoladas, vermelhas, ápice longo-atenuado; pétalas 2-2,2 × 0,3-0,4 cm, oblongas, amarelas, eretas, não espiraladas, ápice agudo, levemente assimétrico; estames inclusos, amarelos; filetes 1,4-1,6 cm compr.; anteras 5-6 mm compr., lineares, base levemente sagitada; gineceu amarelo; ovário c. de $4 \mathrm{~mm}$ compr., súpero; estilete c. de 1,3 cm compr.; estigma $2 \mathrm{~mm}$ compr., conduplicado-espiralado. Frutos 1,3-1,5 cm compr., c. de 6 mm diâm., castanhos, ereto-patentes, perianto persistente; sementes 3-5 mm compr., lineares, bicaudadas, castanhas, com superfície da ala e do corpo com padrão celular distinto.

Material examinado. BRASIL: RIO DE JANEIRO. Santa Maria Madalena, Morro da Torre, no perímetro urbano, afloramentos rochosos com Alcantarea, Barbacenia, Vellozia variegata e Nanuza plicata, 21 ${ }^{\circ} 58^{\prime} 03$ "S e 42 01'03"W, elev. 1.004 m, 17-VI-2004, fl., fr., R.C. Forzza et al. 3440 (RB, SPF); idem, 10-II-2006, fl., fr., R. C. Forzza et al. 4158 (RB); idem, floresceu em cultivo, X-2004, B.R. Silva \& E. Borges 1330 (RB).

Pitcairnia encholirioides foi descrita por Smith (1950) a partir de um único espécime constituído apenas pela inflorescência. Nesse trabalho o autor evidenciou, com muita propriedade, a semelhança da inflorescência desta espécie com as do gênero Encholirium, quando da escolha do epíteto específico. Porém, algumas características marcantes observadas na espécie não foram contempladas na obra original e são aqui apresentadas.

A característica que mais chama atenção em P. encholirioides é a presença de bainhas foliares muito suculentas cobertas por bainhas secas envolvendo um caule reduzido, formando um bulbo típico (figura 2B). O relato de presença de bulbos em espécies de Bromeliaceae não foi encontrado na literatura, porém a estrutura observada em $P$. encholirioides se encaixa perfeitamente na definição apresentada por diversos autores (e.g. Font-Quer 1989). Destacam-se também na espécie a corola actinomorfa, os estames inclusos e as pétalas não espiraladas durante e após a antese (figura 2D), caracteres estes que diferenciam $P$. encholirioides dos demais táxons do gênero. Smith (1950) referiu para a espécie a presença de corola vermelha, porém todos os exemplares examinados no presente estudo apresentam cálice vermelho e corola, estames e gineceu amarelos.

Pitcairnia encholirioides é rara e só foi encontrada em um afloramento muito degradado sujeito à passagem de fogo e pisoteio de animais, dentro de uma propriedade particular em Santa Maria Madalena, sugerindo que esta espécie esteja entre as mais ameaçadas do Rio de Janeiro. Esta única população localizada até o momento apresenta cerca de 900 indivíduos, que ocorrem em local ensolarado juntamente com espécies de Vellozia, Barbacenia (Velloziceae), Tibouchina (Melastomataceae) e Alcantarea (Bromeliaceae).

Agradecimentos - Às pesquisadoras Andrea Costa e Cássia Sakuragui pelas sugestões e ao Paulo Ormindo pelas preciosas ilustrações.

\section{Referências bibliográficas}

FONT-QUER, P. 1989. Diccionario de Botánica. Labor, Barcelona.

HOLST, B.K. 1997. Bromeliaceae. In Flora of the Venezuelan Guayana (Araliaceae-Cactaceae). (P.E. Berry, B.K. Holst \& K. Yatskiervych, eds.). Missouri Botanical Garden, St. Louis, v.3, p. 548-676.

LUTHER, H.E. 2004. An alphabetical list of bromeliad binomials. Bromeliad Society International, Sarasota.

SMITH, L.B. 1950. Bromeliáceas notáveis do herbário do Jardim Botânico do Rio de Janeiro. Arquivos do Jardim Botânico do Rio de Janeiro 10:141-150.

SMITH, L.B. \& DOWNS, R.J. 1974. Pitcairnioideae (Bromeliaceae). Flora Neotropica Monograph 14:1-662.

TATAGIBA, F., ALVES, R.J.V. \& SILVA, B.R. 2004. Two new species of Pitcairnia from Brazil. Selbyana 25:27-32.

WENDT, T. \& CHAMAS, C.C. 1997. As Pitcairnias do leste do Brasil - suas verdadeiras identidades. Bromelia 4:12-18.

WENDT, T., CANELA, M.B.F., MORREY-JONES, J., HENRIQUES, A.B. \& RIOS, R.I. 2000. Recognition of Pitcairnia corcovadensis (Bromeliaceae) at the species level. Systematic Botany 25:389-398. 